\title{
Effects of ankle strengthening exercise program on an unstable supporting surface on proprioception and balance in adults with functional ankle instability
}

\author{
Sun-Young Ha, Jun-Ho Han, Yun-Hee Sung* \\ Department of Physical Therapy, Graduate School of Kyungnam University, Changwon, Korea
}

The present study was conducted to investigate the effect of ankle strengthening exercise applied on unstable supporting surfaces on the proprioceptive sense and balance in adults with functional ankle instability. As for the study method, 30 adults with functional ankle instability were randomly assigned to an ankle strengthening exercise group and a stretching group on unstable supporting surfaces, and the interventions were implemented for $40 \mathrm{~min}$. Before and after the interventions, a digital dual inclinometer was used to measure the proprioceptive sense of the ankle, the Balancia program was used to measure static balance ability, and the functional reach test was used to measure dynamic bal-

\section{INTRODUCTION}

The ankles are important parts that play the role of weight bearing and the role of adjusting lower limb movements during walking and exercise, which are important in daily living (Gao et al., 2011). The ankles as such are frequently damaged in daily life, sports, and leisure activities. Among ankle damage patients, 20\% to $40 \%$ progress into chronic ankle instability (CAI) that shows pain and ankle joint instability (Hardy et al., 2008; Kaminski and Hartsell, 2002). CAI patients are highly likely to be exposed to the risk of other injuries when walking on irregular ground surfaces or conducting sport activities. CAI can be divided into mechanical ankle instability (MAI) and functional ankle instability (FAI). MAI means state of relaxation of the ligament identified through objective physical examinations of the talar tilt and anterior drawer sign and FAI means repetitive ankle sprains or redamage and the complaint of subjective feelings such as ankle giving away in ance ability. In the results, both proprioceptive sense and static dynamic balance ability were significantly different between before and after the intervention in the experimental group $(P<0.05)$. When such results are put together, it can be seen that ankle strengthening exercise applied on unstable supporting surfaces may be presented as an effective treatment method for enhancing the proprioceptive sense and balance ability in adults with functional ankle instability.

Keywords: Ankle instability, Ankle strengthening exercise, Proprioception, Balance

daily living activities (Freeman, 1965; Kaminski et al., 2003).

Balance refers to the ability to keep the center of gravity with minimum postural sways occurring on the bearing surface (Shumway-Cook et al., 1988). Balance training in ankle damage patients can improve postural control and the proprioceptive sense and is widely used as a treatment method to improve the stability of the ankle joints (Arnold et al., 2009; Mattacola and Dwyer, 2002; Ross and Guskiewicz, 2006). The balance ability associated with ankle damage is affected by various forms of sensations, including visual and cutaneous sensations. Among them, the proprioceptive sense is obtaining stimuli through conscious/unconscious processes in the sensory motor system and is divided into motor sense (kinesthesia) that sense the movements of the limbs and joint position sensation that sense the static positions of the limbs. When the proprioceptive sensory function has deteriorated, the postural control ability, protective reflex ability, joint movement ability, and balance ability to respond to postural sways become more
${ }^{*}$ Corresponding author: Yun-Hee Sung (D) https://orcid.org/0000-0002-4877-9784 Department of Physical Therapy, College of Health Sciences, Kyungnam University, 7 Kyungnamdaehak-ro, Masanhappo-gu, Changwon 51767, Korea

Tel: +82-55-249-6334, Fax: +82-50-5999-2173, E-mail: sungpt97@kyungnam.ac.kr Received: February 19, 2018 / Accepted: March 25, 2018
This is an Open Access article distributed under the terms of the Creative Commons Attribution Non-Commercial License (http://creativecommons.org/licenses/by-nc/4.0/) which permits unrestricted non-commercial use, distribution, and reproduction in any medium, provided the original work is properly cited. 
likely to be deteriorated (Bennell et al., 2003; Park, 2007). Studies reported that ankle instability is attributable to the deficit of the proprioceptive sense, and that to improve the proprioceptive sense, balance training through unstable supporting surfaces is necessary (Han et al., 2006; Willems et al., 2002).

To treat FAI and manage activity disorders, proprioceptive sense training using balance training and unstable supporting surfaces, muscle strength exercises for strengthening weakened muscles through elastic band and isokinetic exercise, and manual therapy are implemented among others (Mattacola and Dwyer, 2002; Willems et al., 2002). In particular, although exercises that strengthen ankle muscles, proprioceptive exercises, and exercises that improve balance account for a large part of ankle damage rehabilitation, systematic exercise programs for ankle instability have not yet been concretely presented. Therefore, the present study aimed to investigate whether ankle strengthening exercise programs applied to adults with FAI on unstable supporting surfaces affect the improvement of the proprioceptive sense and balance ability of the ankle joints.

\section{METERIALS AND METHODS}

\section{Participants}

The subjects of the present study were 20 male and female adults recruited using social network service after explaining the purpose and method of the study. The study subjects sufficiently understood the purpose of the present study and voluntarily agreed to participate in the study. The subject selection criterion was those with the score of the Cumberland Ankle Instability Tool (CAIT) not higher than 24 points, which corresponds to FAI and 30 subjects were selected. The selected subjects were randomly divided into an experimental group (ankle exercise applied on unstable supporting surface) and a control group (general exercise).

\section{Functional ankle instability}

FAI was measured using the CAIT scale (Hiller et al., 2006). The evaluation tool consists of nine items that assess subjective feelings such as ankle pain, whether the ankles are instable in daily activities, and recovery time after ankle spraining and defines 24 or lower points out of the full score of 30 points as FAI (Donahue et al., 2011).

\section{Proprioceptive sense}

The proprioceptive sense of the ankles was measured through ankle's active joint position sense tests. A digital dual inclinome- ter (Dualer IQ Digital Inclinometer, J-Tech, Salt Lake City, UT, USA) was used as a tool to measure the ankle joint proprioceptive sense. The test was performed by having the test subject maintain the set targeted angle for $5 \mathrm{sec}$. While his/her vision was blocked, come back to the starting point, and actively return to the set angle. The measurement was conducted three times repeatedly in total and the error angle deviated from the set angle was used as the test result value (Willems et al., 2002).

\section{Static balance}

To assess the static balance ability in the standing position, all participants took off their shoes and stood on the Wii comfortably with their arms put down on both sides when the static balance ability was measured. The measurement was conducted for $30 \mathrm{sec}$ with both eyes open and was repeated three times and the average value was used (Clark et al., 2010). Balancia software ver 2.0 (Mintosys, Seoul, Korea) was used for analysis.

\section{Dynamic balance}

The functional reach test (FRT) is used to measure dynamic balance ability. This method was used to measure a subject to instructed to stand a flat floor at a 5-cm distance from a wall, spread the legs shoulder width apart, stand comfortably, extend the elbows, bend the shoulder at $90^{\circ}$, move the body forward as maximally as possible using only the ankle joint, and extend the body parallel as maximally as possible. Then the distance to the tip of the middle finger (3th metacarpal bone) was measured (In et al., 2016).

\section{Ankle exercise program}

The ankle exercise for experimental group was applied for 40 min as shown in Table 1.

Table 1. Ankle exercise program applied on unstable bearing surfaces

\begin{tabular}{llc}
\hline Step & \multicolumn{1}{c}{ Program } & Time (min) \\
\hline Warm up & Stretching around the ankle joint & 5 \\
Exercise & 30 \\
Bare floor \& aerostep & $\begin{array}{l}\text { Ankle dorsiflexion and plantarflexion in } \\
\text { standing } \\
\text { One leg standing } \\
\text { Ankle plantarflexion in one leg standing } \\
\text { Wobble board }\end{array}$ & $\begin{array}{l}\text { Circle a clockwise and counterclockwise } \\
\text { direction in double support standing }\end{array}$ \\
& $\begin{array}{l}\text { One leg standing } \\
\text { Cool down }\end{array}$ & Standing wall pushing, stretching \\
\hline
\end{tabular}




\section{Statistical analysis}

The statistical analyses were conducted using IBM SPSS Statistics ver. 21.0 (IBM Co., Armonk, NY, USA). Shapiro-Wilk tests were used for homogeneity and normality tests. Paired sample $t$-tests were used to compare the effects appearing before and after exercise within the groups, and independent sample $t$-tests were used to compare the effects between the groups. All values are expressed as mean \pm standard deviation. The significance level of statistical analyses was set to $P<0.05$.

\section{RESULTS}

\section{General characteristics}

The general characteristics of the subjects are as shown in Table 2. The experimental group and the control group showed no significant difference in ages, heights, or body weights $(P>0.05)$.

\section{Effects of ankle exercise on the proprioception sense after intervention}

The angles of dorsiflexion and plantar-flexion after intervention were significantly different in the experimental group $(P<0.05)$, but not in the control group $(P>0.05)$. Changes between before and after exercise in the two groups also showed significant differences $(P<0.05)$ (Table 3).

Table 2. General characteristics of the subjects $(n=30)$

\begin{tabular}{lcccc}
\hline Group & Age $(\mathrm{yr})$ & Height $(\mathrm{cm})$ & Weight $(\mathrm{kg})$ & Sex, male/female \\
\hline Experimental & $20.13 \pm 1.81$ & $163.33 \pm 7.98$ & $65.12 \pm 13.63$ & $4 / 11$ \\
Control & $19.93 \pm 1.01$ & $167.45 \pm 9.39$ & $68.04 \pm 16.25$ & $4 / 11$ \\
\hline
\end{tabular}

Values are presented as mean \pm standard deviation.

Table 3. Comparison of dorsiflexion and plantar flexion before and after ankle exercises $\left({ }^{\circ}\right)$

\begin{tabular}{lccc}
\hline Proprioception & Experimental & Control & $P$-value \\
\hline Dorsiflexion & & & \\
Pre & $4.03 \pm 1.88$ & $3.49 \pm 1.77$ & 0.43 \\
Post & $1.84 \pm 0.87$ & $4.01 \pm 1.62$ & $0.00^{*}$ \\
Post-Pre & $-2.19 \pm 1.68$ & $0.52 \pm 1.25$ & $0.00^{*}$ \\
P-value & $0.00^{*}$ & 0.13 & \\
Plantarflexion & & & \\
Pre & $4.74 \pm 1.93$ & $4.43 \pm 1.67$ & 0.65 \\
Post & $2.03 \pm 0.95$ & $5.28 \pm 1.44$ & $0.00^{*}$ \\
Post-Pre & $-2.71 \pm 1.68$ & $0.85 \pm 2.30$ & $0.00^{*}$ \\
P-value & $0.00^{*}$ & 0.18 & \\
\hline
\end{tabular}

Values are presented as mean \pm standard deviation. ${ }^{*} P<0.05$.

\section{Effects of ankle exercise o static balance after intervention}

Whereas the experimental group showed significant differences in sway area $(P<0.05)$, the control group showed no significant difference $(P>0.05)$. The amounts of changes between before and after exercise in the two groups showed statistically significant differences $(P<0.05)$ (Table 4$)$.

\section{Effects of ankle exercise on dynamic balance after intervention}

In FRT, whereas the experimental group showed significant differences between before and ankle exercise $(P<0.05)$, the control group showed no significant difference $(P>0.05)$. The amounts of changes between before and after exercise in the two groups showed statistically significant differences $(P<0.05)$ (Table 5$)$.

\section{DISCUSSION}

The proprioceptive sense plays important roles of controlling the movements of joints and maintaining stability through receptors located in muscles, tendons, ligaments, and articular capsule (Lephart et al., 1994). In the present results, the error angles of both dorsiflexion and plantar-flexion angles decreased in the experimental group but increased in the control group. Eils and Rosenbaum (2001) reported that when proprioceptive sense exercise was applied to patients with unstable ankles, significant improvement in dorsiflexion and plantar-flexion of joint position sense tests was shown consistently with the results of the present study. The application of muscle strengthening exercise and af-

Table 4. Comparison of static balance before and after ankle exercises $\left(\mathrm{cm}^{2}\right)$

\begin{tabular}{lccc}
\hline Sway area (area 95\%) & Experimental & Control & $P$-value \\
\hline Pre & $10.64 \pm 5.39$ & $8.68 \pm 2.74$ & 0.22 \\
Post & $9.03 \pm 4.20$ & $10.13 \pm 4.25$ & 0.48 \\
Post-pre & $-1.61 \pm 2.74$ & $1.45 \pm 2.75$ & $0.00^{*}$ \\
P-value & $0.04^{*}$ & 0.06 & \\
\hline
\end{tabular}

Values are presented as mean \pm standard deviation ${ }^{*} P<0.05$.

Table 5. Comparison of dynamic balance before and after ankle exercises (cm)

\begin{tabular}{lccc}
\hline Functional reach test & Experimental & Control & $P$-value \\
\hline Pre & $35.56 \pm 6.38$ & $35.61 \pm 4.48$ & 0.97 \\
Post & $36.91 \pm 7.63$ & $35.05 \pm 4.78$ & 0.42 \\
Post-pre & $1.35 \pm 2.17$ & $-0.57 \pm 1.53$ & $0.00^{*}$ \\
$P$-value & $0.03^{*}$ & 0.18 & \\
\hline
\end{tabular}

Values are presented as mean \pm standard deviation. ${ }^{*} P<0.05$. 
fected improvement in muscle strength and the proprioceptive sense (Leanderson et al., 1996). Especially, exercise on unstable supporting surface stimulated proprioceptive sense and unstable supporting surface would be useful for rehabilitation program (Clark and Burden, 2005; Forestier and Toschi, 2005). The ankle exercise program applied on diverse supporting surfaces in this study is also thought to have helped improvement in the proprioceptive sense.

Balance is largely divided into dynamic balance and static balance. Static balance means the ability to stand on a fixed supporting surface without shaking and dynamic balance means the ability to conduct movements independently when the basal plane moves or stimuli are given from the outside (de Haart et al., 2004). Existing studies reported that FAI is associated with the lack of static and dynamic stability and that the lack of static and dynamic stability becomes the cause of ankle redamage (Eils and Rosenbaum, 2001; Matsusaka et al., 2001). In the present study, sway areas were examined using Balancia program to measure static balance before and after the intervention. Decreases in sway areas mean improvement in the balance ability. Changes in balance ability are due to changes in the proprioceptive sense and neuromuscular control and decreases in sways areas mean improvement in static balance ability (Hertel, 2002). It is thought that the exercise program applied on diverse supporting surfaces improved the proprioceptive sense leading to changes in balance ability in the present study. Mattacola and Lloyd (1997) reported that ankle muscle strengthening and proprioceptive sense exercise programs were effective in developing dynamic balance ability. According to our results, dynamic balance ability significantly improved in the experimental group but deteriorated in the control group. A study conducted by Li et al. (2005) reported that the application of Tai chi affected improvement in dynamic balance ability. Improvement in FRT reflects improvement in the forward/backward direction control ability, which dominantly acts in ankle joint strategy (Winter et al., 1998). In the present study, the ankle joint exercise program applied on unstable supporting surfaces is thought to have improved the proprioceptive sense of the ankle to affect improvement in balance ability.

Limitations of the present study include the fact that the number of study subjects was small and the ages of the subjects were limited to young ages. In addition, ankle movements could not be diversely measured so that the results of the present study cannot be easily generalized. Therefore, in future, studies in which such limitations in studies have been supplemented should be conducted.

\section{CONFLICT OF INTEREST}

No potential conflict of interest relevant to this article was reported.

\section{REFERENCES}

Arnold BL, De La Motte S, Linens S, Ross SE. Ankle instability is associated with balance impairments: a meta-analysis. Med Sci Sports Exerc 2009;41:1048-1062.

Bennell KL, Hinman RS, Metcalf BR, Crossley KM, Buchbinder R, Smith M, McColl G. Relationship of knee joint proprioception to pain and disability in individuals with knee osteoarthritis. J Orthop Res 2003;21: 792-797.

Clark RA, Bryant AL, Pua Y, McCrory P, Bennell K, Hunt M. Validity and reliability of the Nintendo Wii Balance Board for assessment of standing balance. Gait Posture 2010;31:307-310.

Clark VM, Burden AM. A 4-week wobble board exercise programme improved muscle onset latency and perceived stability in individuals with a functionally unstable ankle. Phys Ther Sport 2005;6:181-187.

De Haart M, Geurts AC, Huidekoper SC, Fasotti L, van Limbeek J. Recovery of standing balance in postacute stroke patients: a rehabilitation cohort study. Arch Phys Med Rehabil 2004;85:886-895.

Donahue M, Simon J, Docherty CL. Critical review of self-reported functional ankle instability measures. Foot Ankle Int 2011;32:1140-1146.

Eils E, Rosenbaum D. A multi-station proprioceptive exercise program in patients with ankle instability. Med Sci Sports Exerc 2001;33:1991-1998.

Forestier N, Toschi P. The effects of an ankle destabilization device on muscular activity while walking. Int J Sports Med 2005;26:464-470.

Freeman MA. Instability of the foot after injuries to the lateral ligament of the ankle. J Bone Joint Surg Br 1965;47:669-677.

Gao F, Ren Y, Roth EJ, Harvey R, Zhang LQ. Effects of repeated ankle stretching on calf muscle-tendon and ankle biomechanical properties in stroke survivors. Clin Biomech (Bristol, Avon) 2011;26:516-522.

Han SW, Jeong JH, Lee HJ, Lim HJ, Jeon GY, Jeom JH, Jeong RY, Jeong MJ, Jeong SJ, Jo CY. A change of balance ability and EMG analysis of ankle joint around muscle by balance training at an unstable footboard during 4 wks. J Korean Soc Sport Phys Ther 2006;2:11-19.

Hardy L, Huxel K, Brucker J, Nesser T. Prophylactic ankle braces and star excursion balance measures in healthy volunteers. J Athl Train 2008; 43:347-351.

Hertel J. Functional Anatomy, Pathomechanics, and pathophysiology of lateral ankle instability. J Athl Train 2002;37:364-375.

Hiller CE, Refshauge KM, Bundy AC, Herbert RD, Kilbreath SL. The Cumberland ankle instability tool: a report of validity and reliability testing. 
Arch Phys Med Rehabil 2006;87:1235-1241.

In T, Lee K, Song C. Virtual reality reflection therapy improves balance and gait in patients with chronic stroke: randomized controlled trials. Med Sci Monit 2016;22:4046-4053.

Kaminski TW, Buckley BD, Powers ME, Hubbard TJ, Ortiz C. Effect of strength and proprioception training on eversion to inversion strength ratios in subjects with unilateral functional ankle instability. Br J Sports Med 2003;37:410-415.

Kaminski TW, Hartsell HD. Factors contributing to chronic ankle instability: a strength perspective. J Athl Train 2002;37:394-405.

Leanderson J, Eriksson E, Nilsson C, Wykman A. Proprioception in classical ballet dancers. A prospective study of the influence of an ankle sprain on proprioception in the ankle joint. Am J Sports Med 1996;24: 370-374.

Lephart SM, Warner JJ, Borsa PA, Fu FH. Proprioception of the shoulder joint in healthy, unstable, and surgically repaired shoulders. J Shoulder Elbow Surg 1994;3:371-380.

Li F, Harmer P, Fisher KJ, McAuley E, Chaumeton N, Eckstrom E, Wilson NL. Tai Chi and fall reductions in older adults: a randomized controlled trial. J Gerontol A Biol Sci Med Sci 2005;60:187-194.

Matsusaka N, Yokoyama S, Tsurusaki T, Inokuchi S, Okita M. Effect of ankle disk training combined with tactile stimulation to the leg and foot on functional instability of the ankle. Am J Sports Med 2001;29:2530.

Mattacola CG, Dwyer MK. Rehabilitation of the Ankle After Acute Sprain or Chronic Instability. J Athl Train 2002;37:413-429.

Mattacola CG, Lloyd JW. Effects of a 6-week strength and proprioception training program on measures of dynamic balance: a single-case design. J Athl Train 1997;32:127-135.

Park JW. Correlation between joint position sense and severity of pain and range of motion in patients with shoulder dysfunction. J Korea Sport Res 2007;18:443-450.

Ross SE, Guskiewicz KM. Effect of coordination training with and without stochastic resonance stimulation on dynamic postural stability of subjects with functional ankle instability and subjects with stable ankles. Clin J Sport Med 2006;16:323-328.

Shumway-Cook A, Anson D, Haller S. Postural sway biofeedback: its effect on reestablishing stance stability in hemiplegic patients. Arch Phys Med Rehabil 1988;69:395-400.

Willems T, Witvrouw E, Verstuyft J, Vaes P, De Clercq D. Proprioception and muscle strength in subjects with a history of ankle sprains and chronic instability. J Athl Train 2002;37:487-493.

Winter DA, Patla AE, Prince F, Ishac M, Gielo-Perczak K. Stiffness control of balance in quiet standing. J Neurophysiol 1998;80:1211-1221. 